\title{
Oxidation Prevention Properties of Reduced Graphene Oxide Mixed with 1-Octanethiol-Coated Copper Nanopowder Composites
}

\author{
Danee Cho, ${ }^{1}$ Dahyun Choi, ${ }^{1}$ Youngjun Pyo, ${ }^{1}$ Rajendra C. Pawar, ${ }^{1}$ \\ Yongil Kim, ${ }^{2}$ Eric H. Yoon, ${ }^{3}$ and Caroline Sunyong Lee ${ }^{1}$ \\ ${ }^{1}$ Department of Materials Engineering, Hanyang University, 55 Hanyangdaehak-ro, Sangrok-gu, Ansan-si, \\ Gyeonggi-do 426-791, Republic of Korea \\ ${ }^{2}$ School of Advanced Materials Science \& Engineering, Sungkyunkwan University, Suwon-si, Gyeonggi-do 440-746, Republic of Korea \\ ${ }^{3}$ DAECHANG Co., Ltd., Siheung-si, Gyeonggi-do 15076, Republic of Korea
}

Correspondence should be addressed to Caroline Sunyong Lee; sunyonglee@hanyang.ac.kr

Received 11 November 2015; Revised 11 March 2016; Accepted 17 March 2016

Academic Editor: Zhi Li Xiao

Copyright @ 2016 Danee Cho et al. This is an open access article distributed under the Creative Commons Attribution License, which permits unrestricted use, distribution, and reproduction in any medium, provided the original work is properly cited.

\begin{abstract}
1-Octanethiol-coated $\mathrm{Cu}$ nanoparticles were mixed with reduced graphene oxide (rGO) to fabricate $\mathrm{Cu}$ nanoinks with enhanced oxidation prevention. Graphene oxide (GO) was synthesized using modified Hummer's method and rGO was reduced from GO using hydrazine hydrate. Copper nanoinks were fabricated with varying concentrations of rGO (Cu:rGO ratios of $100: 1,500: 1$, and $1000: 1 \mathrm{wt} . \%)$. The coating layers on the copper nanoparticles and rGO were observed using transmission electron microscopy and characterized by X-ray photoemission spectroscopy, X-ray diffraction, and Raman spectroscopy. It was observed that surface roughness increased as the concentration of $\mathrm{rGO}$ in $\mathrm{Cu}$ patterns increased, and an optimized $\mathrm{Cu}: \mathrm{rGO}$ weight ratio of $1,000: 1$ was established. After sintering, the electrical properties and corrosion resistance of copper patterns both with and without rGO were measured and monitored for 200 days. The copper pattern with rGO $(\mathrm{Cu}: \mathrm{rGO}=1,000: 1)$ was found to maintain its initial resistivity $\left(1.63 \times 10^{-7} \Omega \cdot \mathrm{m}\right)$ for 150 days. Corrosion tests were conducted to confirm the oxidation prohibition of rGO. The resistance polarization $\left(R_{p}\right)$ of the copper pattern was measured to be 1.5 times higher than that of the copper pattern without rGO. Thus, rGO was shown to prevent oxidation and improve the conductivity of copper patterns.
\end{abstract}

\section{Introduction}

Copper nanoparticles have been studied extensively for conductive inks due to their thermal and electrical conductivity and low cost. However, copper nanoparticles are easily oxidized, limiting their conductivity after sintering. Polymer coating to prohibit oxidation represents the most studied method for improving the performance of copper nanoparticles [1-5]; however, these coatings can only prevent oxidation before sintering and need to be removed after the sintering process. Graphene can be used for corrosion protection to overcome the limitations of existing protective coatings. Graphene has better electrical and thermal properties compared to copper and is chemically stable [5-7]; therefore, it can prevent oxidation of copper while improving its inherent conductivity $[1,2,8]$. Previous studies on graphene for oxidation prevention were conducted using graphene film fabricated using chemical vapor deposition. However, this fabrication method has limitations such as a high processing cost and difficulties in mass production, and because of the high processing temperature, transition metal catalysts for graphene formation, such as $\mathrm{Cu}, \mathrm{Ni}$, and Pd nanoparticles, lose their shape [9]. Therefore, oxidation prevention using graphene film has only been possible for film-type metals thus far $[1,10]$.

In previous studies, copper nanoparticles have been coated with a 1-Octanethiol vapor self-assembled multilayer (VSAM) to prohibit oxidation before sintering; the particles were successfully dispersed in the 1-Octanol solvent without the use of a dispersant $[11,12]$. In this study, copper nanoinks 
were fabricated by adding reduced graphene oxide (rGO) to prevent oxidation. Sintering of copper nanoinks mixed with $\mathrm{rGO}$ in a range of mixture ratios was studied to establish the effect of rGO on the electrical properties and corrosion resistivity of copper nanoparticles. After sintering, enhanced electrical properties through oxidation prevention were confirmed.

\section{Experimental Process}

2.1. Synthesis of Copper Nanopowders and rGO. Copper nanopowders with a $100 \mathrm{~nm}$ particle size were synthesized using the polyol method described in previous studies. After powder synthesis, the Polyvinylpyrrolidone (PVP) layer coating on the nanopowders was removed using methanol and toluene [13]. These processes were conducted in a glove box under Ar gas conditions to minimize oxidation. After removal of the PVP coating, the surface of the copper nanopowder was coated with 1-Octanethiol using a dry coating system [12]. Coating cycles were conducted six times at 5 minutes per cycle under a high vacuum $\left(4.0 \times 10^{-6}\right.$ torr $)$. GO was synthesized using Hummer's method, and rGO was synthesized by GO reduction using hydrazine hydrate [14, 15]. The 1-Octanethiol coating on copper nanoparticles and the thickness and shape of rGO sheets were observed by field-emission scanning electron microscopy (FE-SEM). Xray diffraction (XRD) and Raman spectroscopy were used to confirm the successful reduction of GO to rGO. Finally, thickness and roughness of the fabricated copper patterns were measured for comparison using a profiler (ET200, Kosaka, Japan).

2.2. Fabrication and Characterization of Copper Nanoink with $r G O$. Copper nanoink was fabricated by mixing 1-Octanethiol-coated copper nanopowders with rGO. 1Octanol was used as the solvent because of its dispersion stability with 1-Octanethiol-coated copper nanoparticles [11]; therefore, the ink was fabricated without any dispersion stabilizer or surfactant. To confirm the effect of rGO on copper nanoink, mixtures with ratios (wt.\%) of copper nanopowders to rGO of $100: 1,500: 1$, and $1000: 1$ were composed. The concentration of copper nanoparticles with rGO in the Octanol solvent was 20 wt.\%. To disperse rGO sheets in the copper nanoink, rGO was mixed with 1-Octanol and dispersed for $1 \mathrm{hr}$, and the rGO/1-Octanol solution was then mixed with the copper nanoparticles. The completed ink solution was then dispersed using an ultrasonic generator for 30 minutes. After dispersion, $3 \mathrm{~mL}$ of copper nanoink was dropped onto a glass substrate to make a pattern size of $2 \times$ $2 \mathrm{~cm}^{2}$.

Sintering was conducted under $\mathrm{H}_{2}$ gas $(500 \mathrm{sccm})$ at a heating rate of $5^{\circ} \mathrm{C} / \mathrm{min}$ (Figure 1) [16]. The line resistivity of the sintered patterns was measured immediately after sintering and monitored for 200 days. Finally, the corrosion resistance was measured in $3 \mathrm{wt} . \% \mathrm{NaCl}$ aqueous solution.

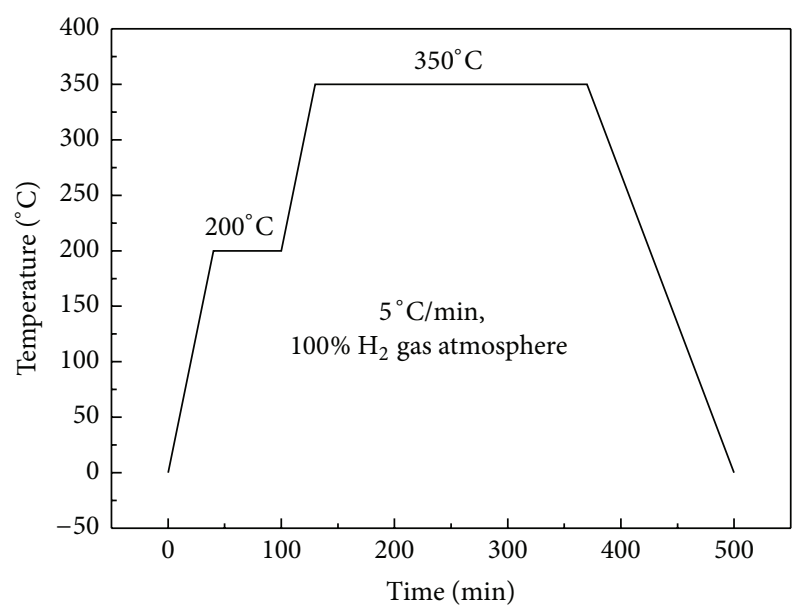

FIGURE 1: Sintering profile of copper patterns.

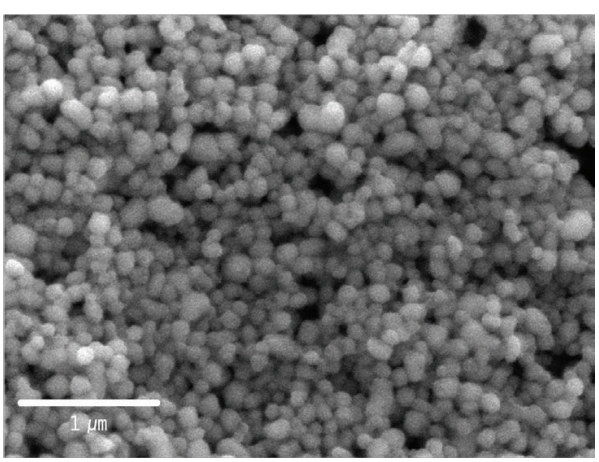

FIGURE 2: SEM image of synthesized copper nanopowders using polyol method.

\section{Results and Discussion}

3.1. Analysis of Copper Nanopowders and rGO. Figure 2 shows SEM image of the $100 \mathrm{~nm}$ sized copper nanopowders which were coated with PVP using polyol method. It was confirmed that the copper nanoparticles were synthesized with $\mathrm{Cu}$ nanoparticles' uniform size and shape as shown in Figure 2. After removal of the PVP coating, 1-Octanethiol layer was entirely formed onto the copper nanopowders using a dry coating system [12]. Figure 3 shows TEM images of 1Octanethiol-coated nanopowders, with uniform coating. Its diffraction pattern in the inset shows that the surface has not been oxidized. Oxidation prevention by 1-Octanethiol has been discussed previously [16, 17]. Therefore, it was confirmed that 1-Octanethiol layer was successfully coated on surface of each copper nanoparticle via coating system through TEM analysis.

Figure 4 shows the shape of the graphene oxide (GO) and reduced graphene oxide (rGO) sheets. In the case of rGO, compared to the GO sheet, it was thinner than GO sheet because of forming wrinkles on the surface of rGO sheet during reduction process and GO sheets were separated into thin rGO sheet (Figures 4(a) and 4(b)). In fact, it shows that GO consisted of a minimum of two or more sheets whereas 


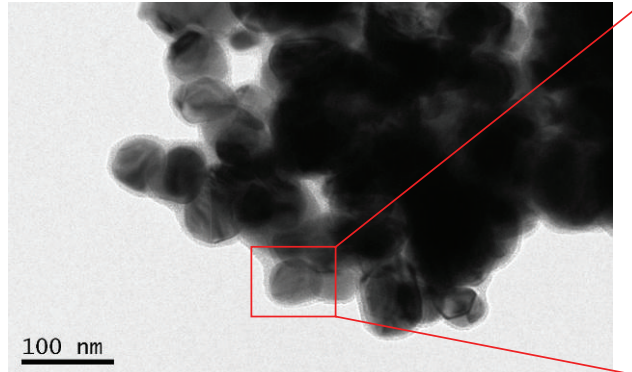

(a)

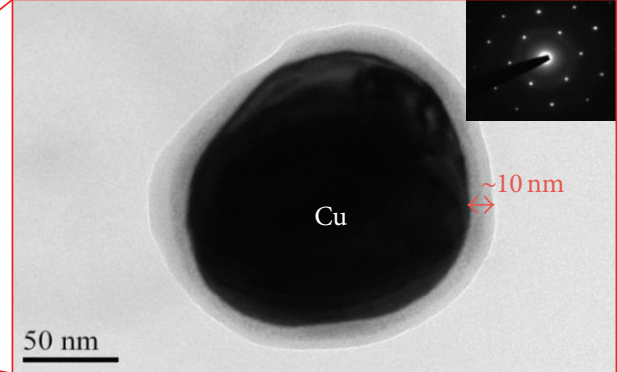

(b)

FIGURE 3: TEM image of (a) 1-Octanethiol-coated copper nanoparticles using dry coating system and (b) one of the copper nanoparticles coated with 1-Octanethiol showing its thickness and its diffraction pattern on the surface (inset).

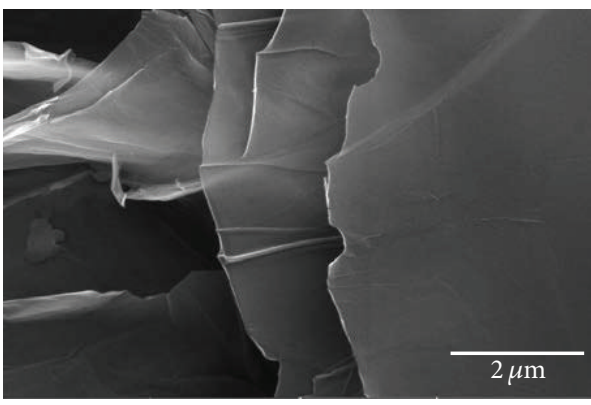

(a)

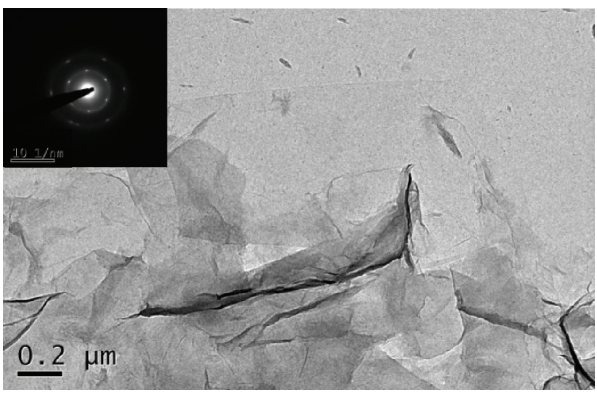

(c)

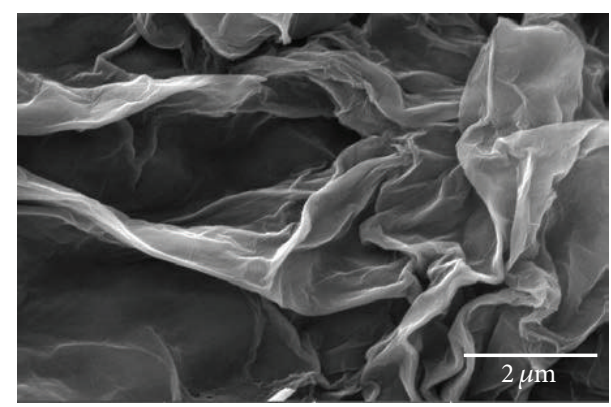

(b)

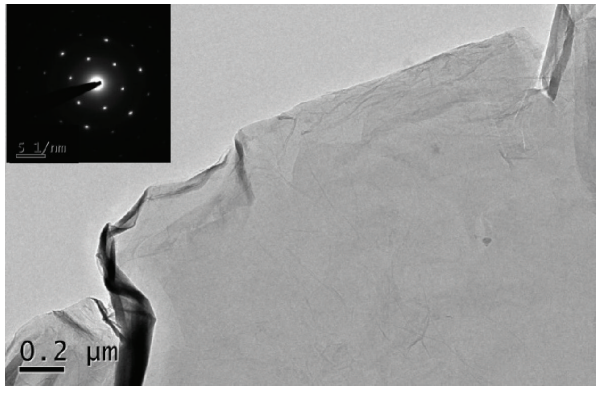

(d)

FIGURE 4: SEM images of (a) graphene oxide and (b) reduced graphene oxide (rGO) and TEM image of (c) graphene oxide, (d) reduced graphene oxide (rGO), and its diffraction patterns (inset).

rGO sheet shows clearly thin layer with diffraction pattern shown in Figures 4(c) and 4(d). Therefore, rGO shows a clear and crystalline diffraction pattern because it was almost separated into thin sheets with no overlap. In contrast, the diffraction pattern for the GO sheets is similar to that of the amorphous phase, as shown in the inset of Figure 4(c), due to its overlap as well as functional groups on the GO surface [18].

To confirm the reduction of GO to rGO, X-ray diffraction and Raman spectroscopy analyses were conducted as shown in Figures 5 and 6 . The XRD analysis for GO has a sharp peak at around $11^{\circ}$ (interlayer distance of $7.5 \AA$ ), confirming the exfoliation of the GO sheets due to functional groups on the surface. In contrast, rGO has a broad peak at $20.4^{\circ} \sim 24.8^{\circ}$ (interlayer distance: $4.41 \sim 3.50 \AA$ ), similar to the interlayer distance of graphene, which is $3.5 \AA$ [19]. Therefore, based on the XRD analysis, it can be confirmed that the rGO sheets have similar properties to graphene and that complete reduction of the GO took place, removing functional groups on the GO surface. The Raman spectra shown in Figure 6 show similar peaks, in agreement with [20].

The Raman spectrum for graphite has a sharp peak around $1580 \mathrm{~cm}^{-1}$ ( $\mathrm{G}$ band), indicating the in-plane vibration of $\mathrm{sp}^{2}$ carbon atoms [20]. The peak around $1350 \mathrm{~cm}^{-1}$ is the $\mathrm{D}$ band which is caused by a scattered signal at the edge of graphite due to defects [20,21]. Unlike graphite, GO and rGO have peaks at similar positions; however, the intensity ratio between the $D$ and $G$ band differs between GO and graphite sheets; a higher D band to $G$ band intensity ratio for $\mathrm{GO}$ is observed compared to that of graphite, because the 

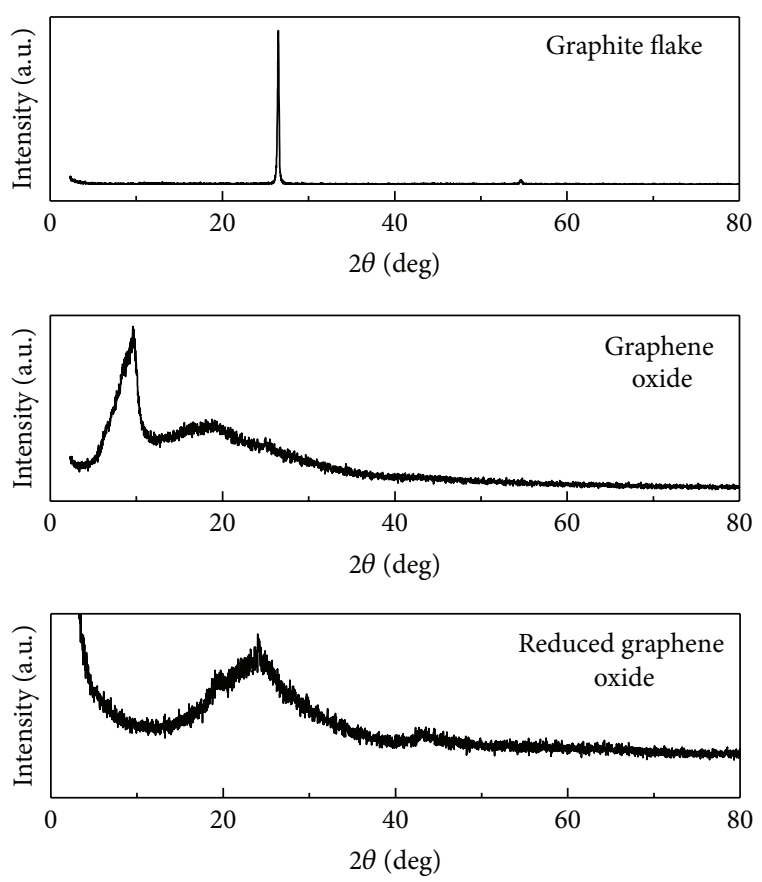

FIGURE 5: XRD results of graphite flake, GO, and rGO.

TABLE 1: Line resistivities of copper patterns with varying weight ratio of rGO.

\begin{tabular}{ccc}
\hline \multicolumn{3}{c}{ Average line resistivities $\left(\times 10^{-7} \Omega \cdot \mathrm{m}\right)$} \\
\hline & $100: 1$ & $2.45 \pm 0.33$ \\
$\mathrm{Cu}:$ rGO (wt.\%) & $500: 1$ & $1.62 \pm 0.51$ \\
& $1000: 1$ & $1.63 \pm 0.33$ \\
\hline $100 \% \mathrm{Cu}$ & & $2.38 \pm 0.34$ \\
\hline
\end{tabular}

functional group on the surface of GO changes the structure of the graphite sheet and increases the intensity of the $\mathrm{D}$ band $[22,23]$. For rGO, the intensity of the $\mathrm{D}$ band is higher than that of the $\mathrm{G}$ band, whereas the opposite $\mathrm{D}$ to $\mathrm{G}$ band ratio is found for GO. This is because toxic nitrogen gas, evolved during the reduction from GO to rGO, becomes absorbed on the rGO surface $[22,24]$.

3.2. Electrical Properties of Copper with rGO. To compare the effect of rGO on copper patterns, the electrical properties of copper patterns both with and without rGO were characterized by measuring line resistivities. The initial resistivities of copper patterns with $\mathrm{rGO}(\mathrm{Cu}: \mathrm{rGO}=500: 1$ and $1,000: 1)$ were measured to be $1.32 \times 10^{-7} \Omega \cdot \mathrm{m}$ and $1.33 \times 10^{-7} \Omega \cdot \mathrm{m}$, respectively. These values were lower than that of the copper pattern without rGO, as shown in Table 1.

Resistivities were monitored for 40 days to compare differences among various patterns. Figure 7 shows changes in line resistivity with time for copper patterns without rGO and with rGO at each ratio. The line resistivity of the copper pattern with a 1,000:1 Cu:rGO ratio shows very little change over time; in contrast, the other $\mathrm{Cu}$ patterns (500:1 and 100:1 Cu:rGO ratios) show significant changes.
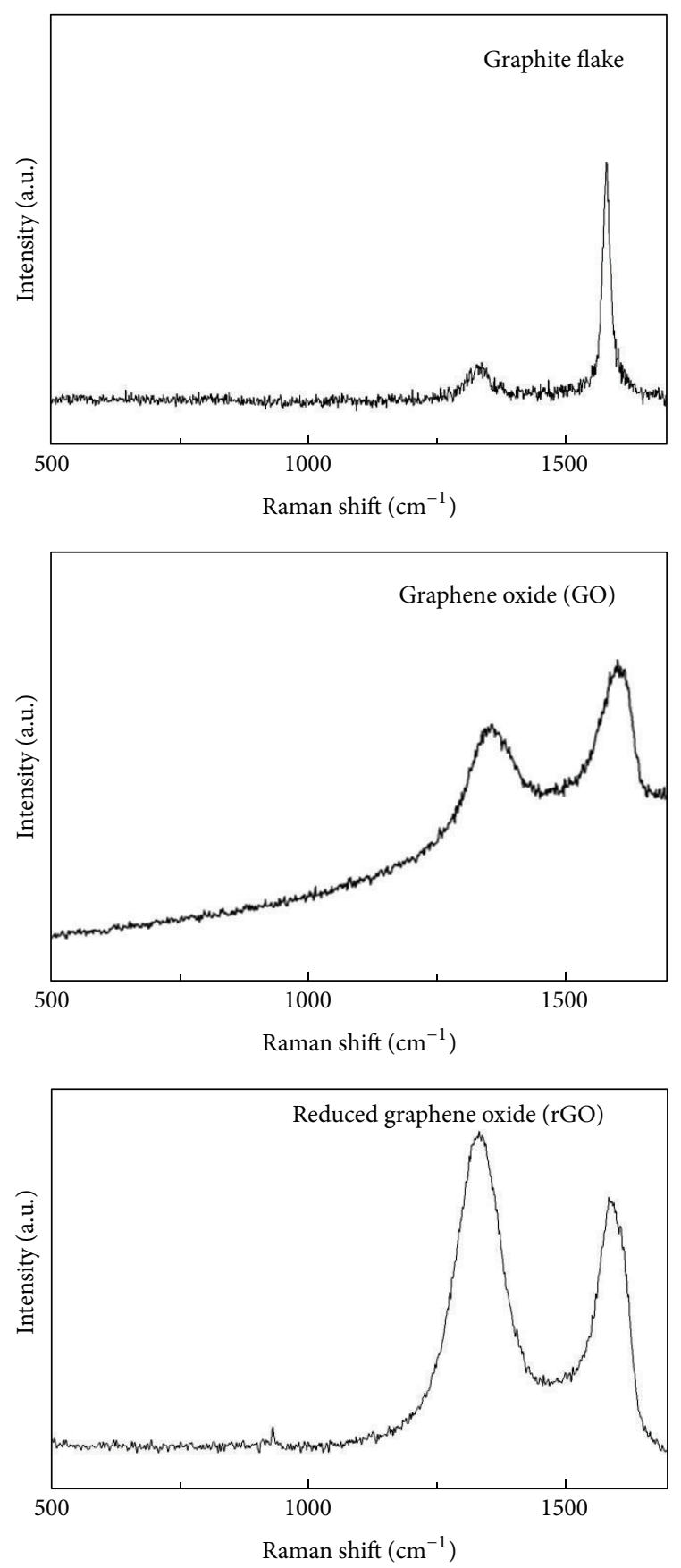

FIGURE 6: Raman spectroscopy results of graphite flake, GO, and rGO.

Significant differences in the resistivity trend were observed upon comparing the line resistivity of the $\mathrm{Cu}$ pattern with a $1,000: 1$ ratio to that without rGO. It is confirmed that an optimized $\mathrm{Cu}$ :rGO mixture ratio exists and that this optimized ratio in a copper pattern can enhance electrical properties and prevent oxidation over time.

Figure 8 shows its correlation between amount of rGO added and roughness of patterns using profiler. The copper pattern without rGO has lower roughness than copper patterns with varying rGO wt.\% of $\mathrm{Cu}: \mathrm{rGO}=100: 1$ and 


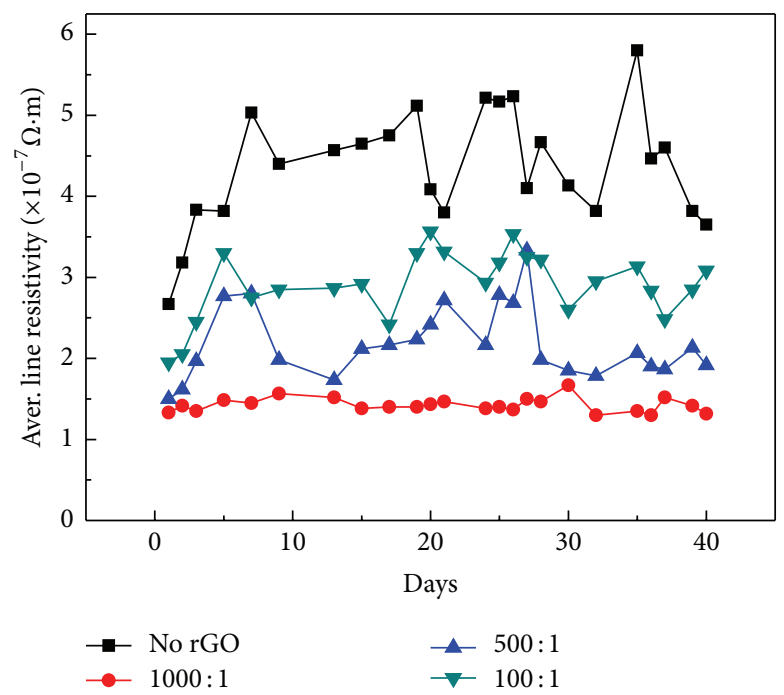

FIGURE 7: Line resistivity measurement results of copper patterns with varying rGO concentrations (wt.\%) of $\mathrm{Cu}: \mathrm{rGO}=100: 1, \mathrm{Cu}: \mathrm{rGO}=$ $500: 1$, and $\mathrm{Cu}: \mathrm{rGO}=1,000: 1$ and no rGO (only Cu pattern), over 40 days.

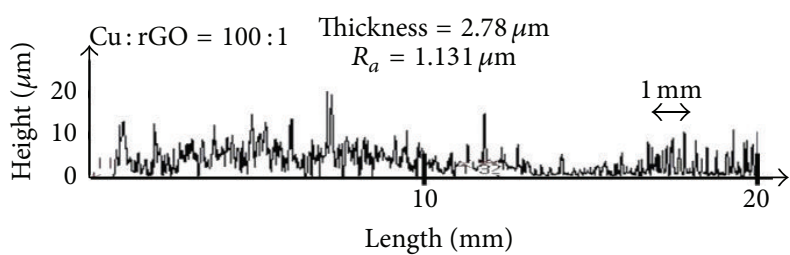

(a)

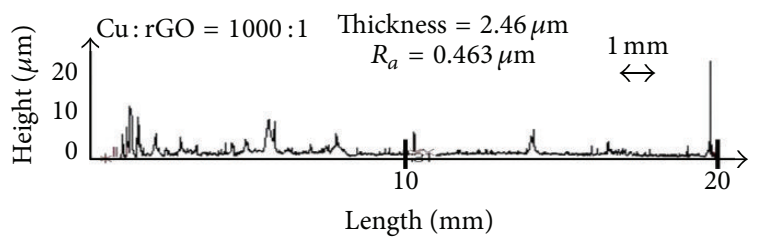

(c)

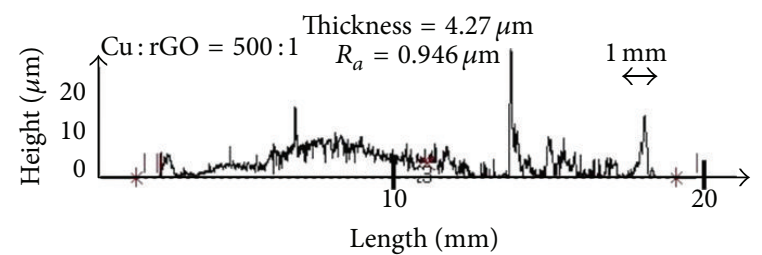

(b)

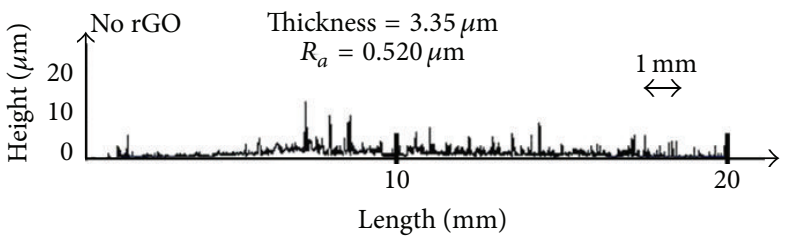

(d)

FIGURE 8: The thickness with roughness of copper patterns with varying rGO concentrations (wt.\%) of $\mathrm{Cu}: \mathrm{rGO}=100: 1, \mathrm{Cu}: \mathrm{rGO}=500: 1$, and $\mathrm{Cu}: \mathrm{rGO}=1,000: 1$ and no $\mathrm{rGO}$ (only Cu pattern).

$\mathrm{Cu}: \mathrm{rGO}=500: 1$. Overall, the copper patterns with high wt.\% of rGO show the increasing trend of surface roughness. To further investigate the cause, SEM analysis was performed in order to identify the effect of rGO on the surface roughness of copper patterns as shown in Figure 9.

SEM was used to study its effect of incorporating rGO into 1-Octanethiol-coated $\mathrm{Cu}$ nanoparticles on the surface roughness, as shown in Figure 9. For Cu patterns with 1,000:1 $\mathrm{Cu}$ : rGO ratio in wt.\%, rGO sheets seem to be well-dispersed in the $\mathrm{Cu}$ pattern. However, as the mixing ratio of adding rGO increases from $1,000: 1$ to $100: 1$, there is an increase in agglomerated rGO sheets on the surface, leaving porous structure that will affect electrical properties. This indicates that rGO sheets were not dispersed uniformly as the mixing ratio increased. Moreover, topology of $\mathrm{Cu}$ patterns without rGO (Figure $9(\mathrm{~d})$ ) seems to be more porous than the one for $\mathrm{Cu}$ pattern with 1000:1 Cu:rGO ratio in weight \% (Figure 9(c)). Based on these results, it was confirmed that there is optimum amount of $\mathrm{rGO}$, minimizing its surface roughness of copper patterns which was found to be 1,000:1 $\mathrm{Cu}$ : rGO ratio in weight \%. As shown in the roughness data in Figure 8, the $\mathrm{Cu}$ pattern, with $\mathrm{Cu}$ : rGO being 1000:1 in wt.\%, seems to have the lowest roughness value, compared to that of $\mathrm{Cu}$ pattern without rGO. This profiler result can be confirmed using SEM images showing the surface of various $\mathrm{Cu}$ patterns, as shown in Figure 9. The $\mathrm{Cu}$ patterns without $\mathrm{rGO}$ seem to be porous with agglomeration among themselves, leaving porous structure. However, these pores seem to be filled by rGO with its minimum amount of $1 / 1000$ in wt.\%. If the amount of rGO goes beyond $1000: 1$ in $\mathrm{Cu}$ : rGO ratio in weight percent, the roughness seems to increase, leaving those extra rGO on the surface. These 

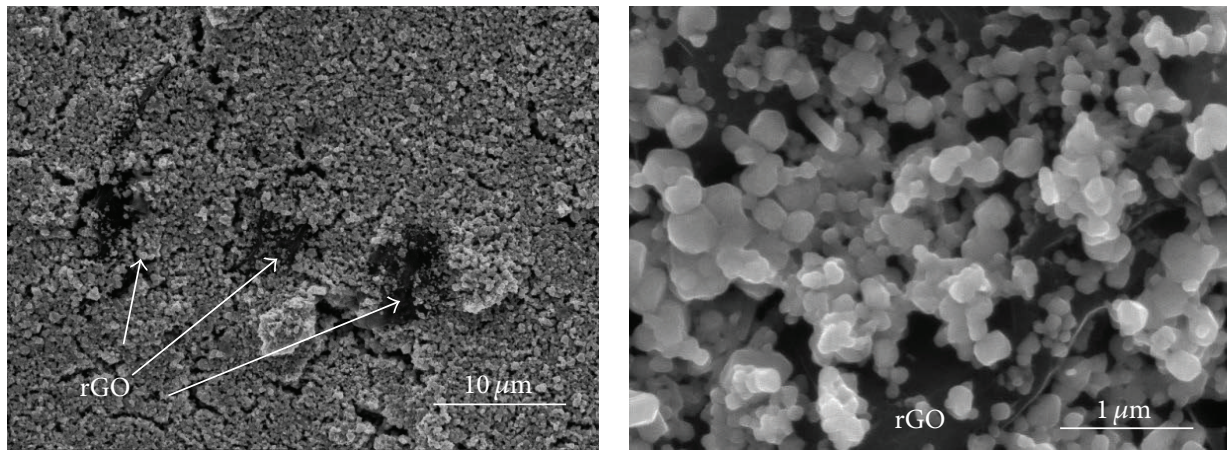

(a)
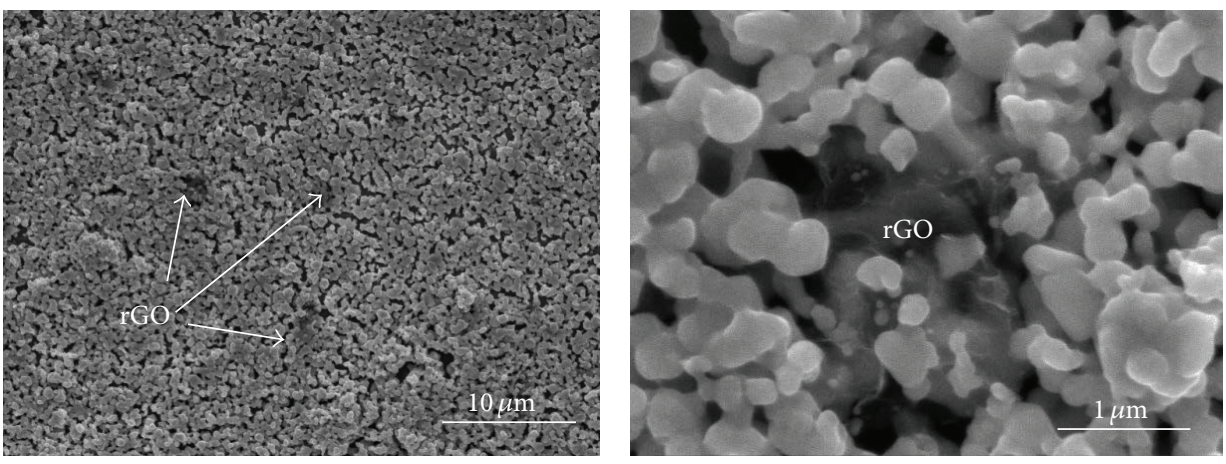

(b)
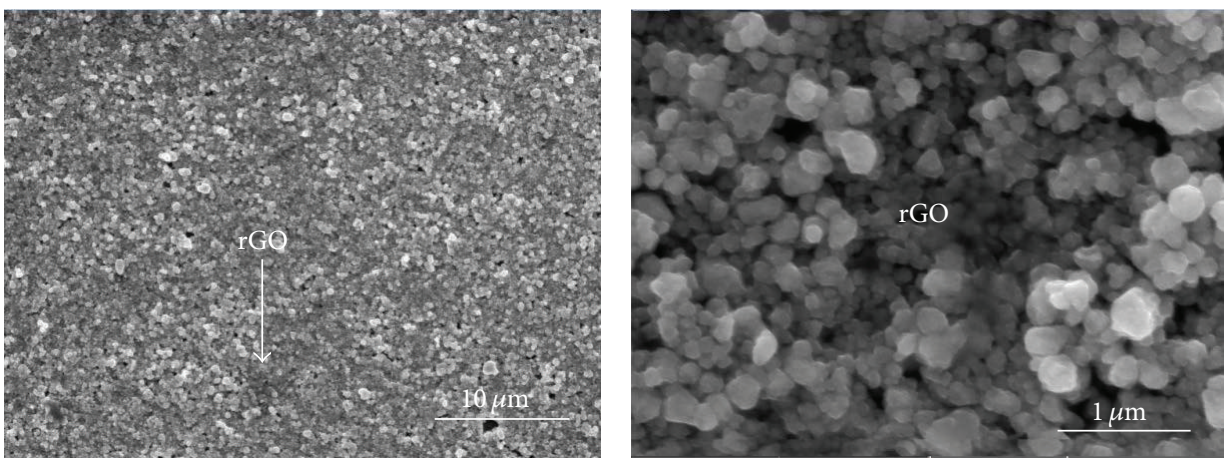

(c)
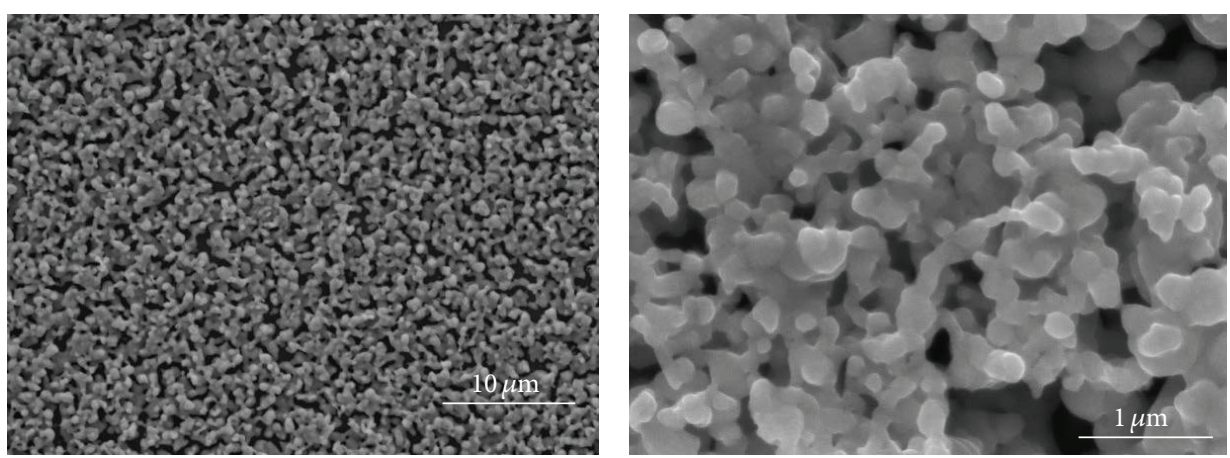

(d)

FIGURE 9: SEM images showing surface of copper patterns with varying rGO concentrations (wt.\%) of (a) $\mathrm{Cu}: \mathrm{rGO}=100: 1,(\mathrm{~b}) \mathrm{Cu}: \mathrm{rGO}=$ $500: 1$, and (c) $\mathrm{Cu}: \mathrm{rGO}=1,000: 1$ and (d) no rGO (only Cu pattern). 


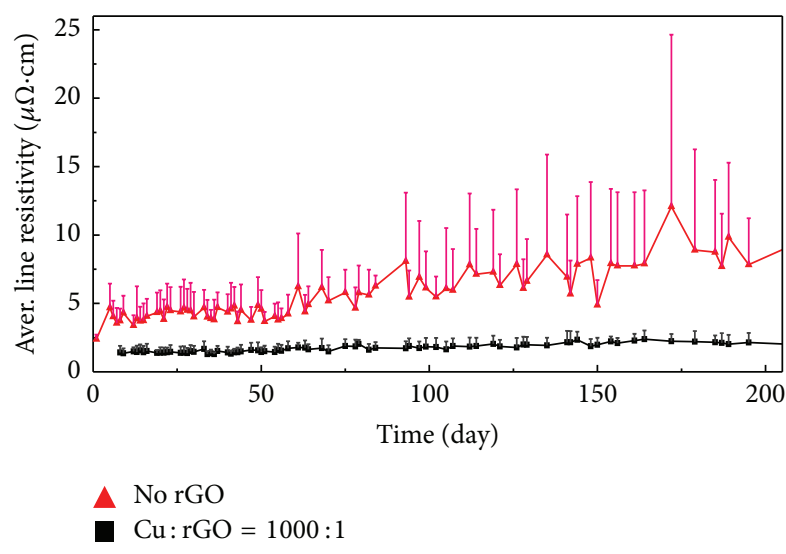

FIGURE 10: Average line resistivity measurement of the copper patterns over 200 days.

seem to give more porous structure with rougher surface, compared to the ones with no rGO and rGO added with its $\mathrm{Cu}: \mathrm{rGO}$ ratio of $1000: 1$. For the case of rGO with its $\mathrm{Cu}$ : rGO weight ratio of $100: 1$, the excessive amount of rGO is exposed on the surface, resulting in the formation of cracks, as shown in Figure 9(a). Therefore, this rough surface resulted in significant change in the resistivity of copper patterns over time, as shown in Figure 7. Therefore, well-dispersed rGO seems to induce electrical stability in the copper patterns by preventing oxidation, and the optimum $\mathrm{Cu}: \mathrm{rGO}$ ratio for good dispersion is found to be $1,000: 1$ in wt.\%.

\subsection{Corrosion Resistance of $r G O$}

3.3.1. Long Term Measurement of Electrical Resistivities. After establishing the optimum concentration of $\mathrm{rGO}$ in $\mathrm{Cu}$ patterns, the line resistivity of the pattern with the 1,000:1 $(\mathrm{Cu}: \mathrm{rGO})$ mixture ratio as well as the pattern without $\mathrm{rGO}$ was observed for 200 days (Figure 10). The line resistivity of the copper pattern with rGO showed very little change for 130 days and increased slightly after 150 days; in contrast, the copper pattern without rGO showed unstable changes in resistivity for the first 50 days, which dramatically increased after this time. The copper pattern without rGO partially oxidized within the first time period and underwent significant oxidization after 50 days, resulting in a rapid increase in line resistivity. Error bars for the line resistivity time series are also shown in Figure 10, and a significant difference in standard deviation between the two copper patterns can be observed. The standard deviation of the copper pattern without rGO was three times that of the copper pattern with rGO over the first 50 days, and this difference increased more than tenfold after 50 days. Therefore, the copper pattern incorporating an optimized rGO concentration showed remarkable stability in electrical resistivity as well as a small standard deviation.

3.3.2. Corrosion Resistance. To further investigate the corrosion resistance characteristics of $\mathrm{Cu}$ patterns with and without rGO, electrochemical corrosion tests were performed in $3 \mathrm{wt} . \% \mathrm{NaCl}$ aqueous solution to obtain polarization

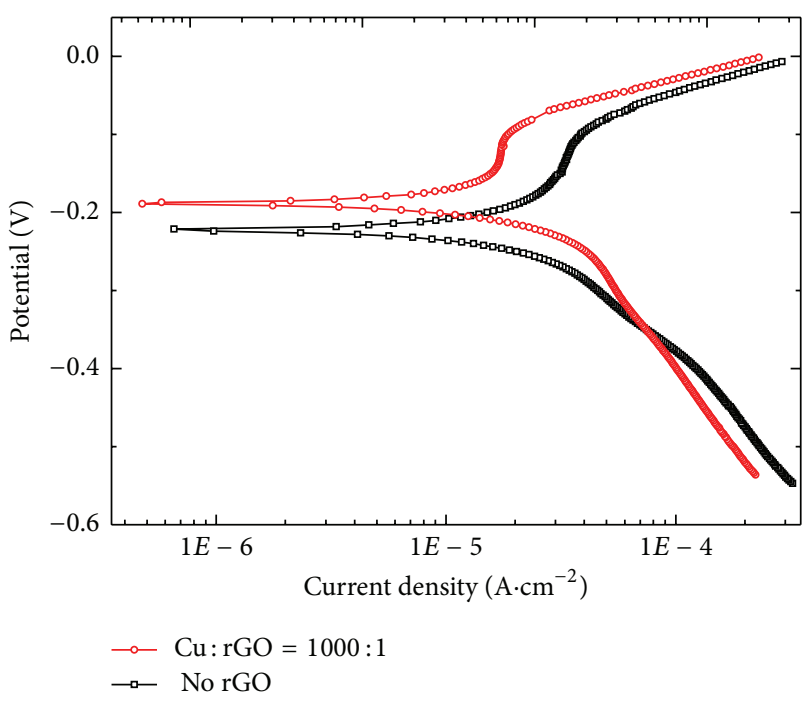

FIGURE 11: Polarization curve of copper patterns measured in $3 \mathrm{wt} . \%$ $\mathrm{NaCl}$ aqueous solution.

curves through Tafel extrapolation, as shown in Figure 11. Polarization curves and polarization resistance, $R_{p}$, were calculated using the Stern-Geary equation, to relate polarization resistance to charge transfer resistance. $R_{p}$ for the copper pattern with $\mathrm{rGO}$ at a $\mathrm{Cu}: \mathrm{rGO}$ ratio of $1,000: 1$ was measured to be $-1.1 \times 10^{8}$ while $R_{p}$ for the copper pattern without rGO was measured to be $-7.0 \times 10^{7}$. The copper pattern with rGO has $R_{p}$ value 1.5 times higher than that of the pattern without rGO. A higher $R_{p}$ value indicates interrupted polarization and better corrosion resistance; hence, this result supports the conclusion that the copper pattern with rGO has better oxidation inhibition properties than the pattern without rGO.

\section{Conclusion}

The effect of adding rGO to copper patterns was studied. Copper nanoinks were fabricated by mixing rGO with $\mathrm{Cu}$ particles in varying weight ratios. Before ink fabrication, copper nanoparticles were coated with 1-Octanethiol VSAM to minimize oxidation before sintering. To confirm the effect of $\mathrm{rGO}$ on copper patterns, copper nanoinks were fabricated with varying concentrations of $\mathrm{rGO}(\mathrm{Cu}: \mathrm{rGO}$ ratios of $100: 1$, $500: 1$, and 1,000:1 (wt.\%)). After sintering, the electrical properties and corrosion resistance of copper patterns with and without rGO were measured and monitored for 200 days. The trend of electrical properties indicated that the surface roughness of copper pattern increased with increasing weight $\%$ of rGO. Moreover, the sample surface with higher roughness accelerates the oxidation of $\mathrm{Cu}$ pattern over time, resulting in fluctuation. Therefore, well-dispersed rGO seems to induce electrical stability in the copper patterns by preventing oxidation, and the optimum $\mathrm{Cu}$ : $\mathrm{rGO}$ ratio for good dispersion is found to be 1,000:1wt.\%. The copper pattern with $\mathrm{rGO}(\mathrm{Cu}: \mathrm{rGO}=1,000: 1)$ was found to maintain its initial resistivity $\left(1.63 \times 10^{-7} \Omega \cdot \mathrm{m}\right)$ for 150 days, whereas the resistivity of the copper pattern without rGO changed 
significantly after 50 days. Corrosion tests were conducted using $3 \mathrm{wt} . \% \mathrm{NaCl}$ aqueous solution, and the resistance polarization $\left(R_{p}\right)$ of the copper pattern with rGO $(\mathrm{Cu}: \mathrm{rGO}$ ratio of $1,000: 1)$ was measured to be 1.5 times higher than that of the pattern without rGO. It can be concluded that the addition of an optimized amount of rGO to the copper pattern improved oxidation prevention and its electrical conductivity.

\section{Competing Interests}

The authors declare that they have no competing interests.

\section{Acknowledgments}

This work was supported by the Energy Efficiency \& Resources Core Technology Program of the Korea Institute of Energy Technology Evaluation and Planning (KETEP), by granted financial resource from the Ministry of Trade, Industry and Energy, Republic of Korea (no. 20142020103730), and by the National Research Foundation of Korea (NRF) grant from the Korea government (MEST) (no. 2013R1A1A2074605). This work was supported by the Human Resources Development program (no. 20154030200680) of the Korea Institute of Energy Technology Evaluation and Planning (KETEP) grant funded by the Korea government Ministry of Trade, Industry and Energy.

\section{References}

[1] D. Prasai, J. C. Tuberquia, R. R. Harl, G. K. Jennings, and K. I. Bolotin, "Graphene: corrosion-inhibiting coating," ACS Nano, vol. 6, no. 2, pp. 1102-1108, 2012.

[2] S. Magdassi, M. Grouchko, and A. Kamyshny, "Copper nanoparticles for printed electronics: routes towards achieving oxidation stability," Materials, vol. 3, no. 9, pp. 4626-4638, 2010.

[3] G. Spinks, A. J. Dominis, G. G. Wallace, and D. E. Tallman, "Electroactive conducting polymers for corrosion control: part 2. Ferrous metals," Journal of Solid State Electrochemistry, vol. 6, no. 2, pp. 85-100, 2002.

[4] A. T. Lusk and G. K. Jennings, "Characterization of selfassembled monolayers formed from sodium S-alkyl thiosulfates on copper," Langmuir, vol. 17, no. 25, pp. 7830-7836, 2001.

[5] C. Mattevi, H. Kim, and M. Chhowalla, "A review of chemical vapour deposition of graphene on copper," Journal of Materials Chemistry, vol. 21, no. 10, pp. 3324-3334, 2011.

[6] L. Liu, S. Ryu, M. R. Tomasik et al., "Graphene oxidation: thickness-dependent etching and strong chemical doping," Nano Letters, vol. 8, no. 7, pp. 1965-1970, 2008.

[7] F. Bonaccorso, L. Colombo, G. Yu et al., "Graphene, related twodimensional crystals, and hybrid systems for energy conversion and storage," Science, vol. 347, no. 6217, Article ID 1246501, 2015.

[8] S. Chen, L. Brown, M. Levendorf et al., "Oxidation resistance of graphene-coated $\mathrm{Cu}$ and $\mathrm{Cu} / \mathrm{Ni}$ alloy," ACS Nano, vol. 5, no. 2, pp. 1321-1327, 2011.

[9] R. Wang, Y. Hao, Z. Wang, H. Gong, and J. T. L. Thong, "Largediameter graphene nanotubes synthesized using $\mathrm{Ni}$ nanowire templates," Nano Letters, vol. 10, no. 12, pp. 4844-4850, 2010.
[10] S.-J. Byun, H. Lim, G.-Y. Shin et al., "Graphenes converted from polymers," Journal of Physical Chemistry Letters, vol. 2, no. 5, pp. 493-497, 2011.

[11] D. Cho, J.-H. Baik, J.-H. Park, and C. S. Lee, "Investigation of dispersion stability of conductive nano ink using 1-octanethiol coated copper nano powders," Journal of the Korean Ceramic Society, vol. 49, no. 5, pp. 417-422, 2012.

[12] J. Kwon, S. Park, Y.-S. Kim, and C. S. Lee, "Controlled thicknesses of vaporized self-assembled multilayers on copper nanopowders under ultra-high vacuum (UHV)," Journal of Nanoscience and Nanotechnology, vol. 12, no. 2, pp. 1206-1210, 2012.

[13] M.-R. Seong, J. Kwon, G.-Y. Lee, D.-K. Kim, Y.-S. Kim, and C. S. Lee, "Optimization of surface coating condition using vapor form of alkanethiol on $\mathrm{Cu}$ nano powders for the application of oxidation prevention," Applied Surface Science, vol. 256, no. 8, pp. 2332-2336, 2010.

[14] L. Staudenmaier, "Verfahren zur darstellung der graphitsaure," Berichte der Deutschen Chemischen Gesellschaft, vol. 31, no. 2, pp. 1481-1487, 1898.

[15] P. P. Wibroe, S. V. Petersen, N. Bovet, B. W. Laursen, and S. M. Moghimi, "Soluble and immobilized graphene oxide activates complement system differently dependent on surface oxidation state," Biomaterials, vol. 78, pp. 20-26, 2016.

[16] J. Her, D. Cho, and C. S. Lee, "Synthesis of conductive nano ink using 1-octanethiol coated copper nano powders in 1-octanol for low temperature sintering process," Materials Transactions, vol. 54, no. 4, pp. 599-602, 2013.

[17] J. Kwon, S. Park, T. H. Lee, J.-M. Yang, and C. S. Lee, "Investigation of oxidation inhibition properties of vaporized self-assembled multilayers on copper nanopowders," Applied Surface Science, vol. 257, no. 11, pp. 5115-5120, 2011.

[18] S. H. Huh, "Thermal reduction of graphene oxide", in Physics and Applications of Graphene-Experiments, S. Mikhailov, Ed., chapter 5, pp. 73-90, InTech, Rijeka, Croatia, 2011.

[19] S. Lee, J. Hong, J. H. Koo et al., "Synthesis of few-layered graphene nanoballs with copper cores using solid carbon source," ACS Applied Materials and Interfaces, vol. 5, no. 7, pp. 2432-2437, 2013.

[20] Z. Ni, Y. Wang, T. Yu, and Z. Shen, "Raman spectroscopy and imaging of graphene," Nano Research, vol. 1, no. 4, pp. 273-291, 2008.

[21] H. A. Becerril, J. Mao, Z. Liu, R. M. Stoltenberg, Z. Bao, and Y. Chen, "Evaluation of solution-processed reduced graphene oxide films as transparent conductors," ACS Nano, vol. 2, no. 3, pp. 463-470, 2008.

[22] Z. Ye, H. Tai, T. Xie et al., "A facile method to develop novel $\mathrm{TiO}_{2} / \mathrm{rGO}$ layered film sensor for detecting ammonia at room temperature," Materials Letters, vol. 165, pp. 127-130, 2016.

[23] D. Li, M. B. Müller, S. Gilje, R. B. Kaner, and G. G. Wallace, "Processable aqueous dispersions of graphene nanosheets," Nature Nanotechnology, vol. 3, no. 2, pp. 101-105, 2008.

[24] KDB Industrial Bank, Technology Trend of the New Material Graphene, KDB Industrial Bank, 2011. 

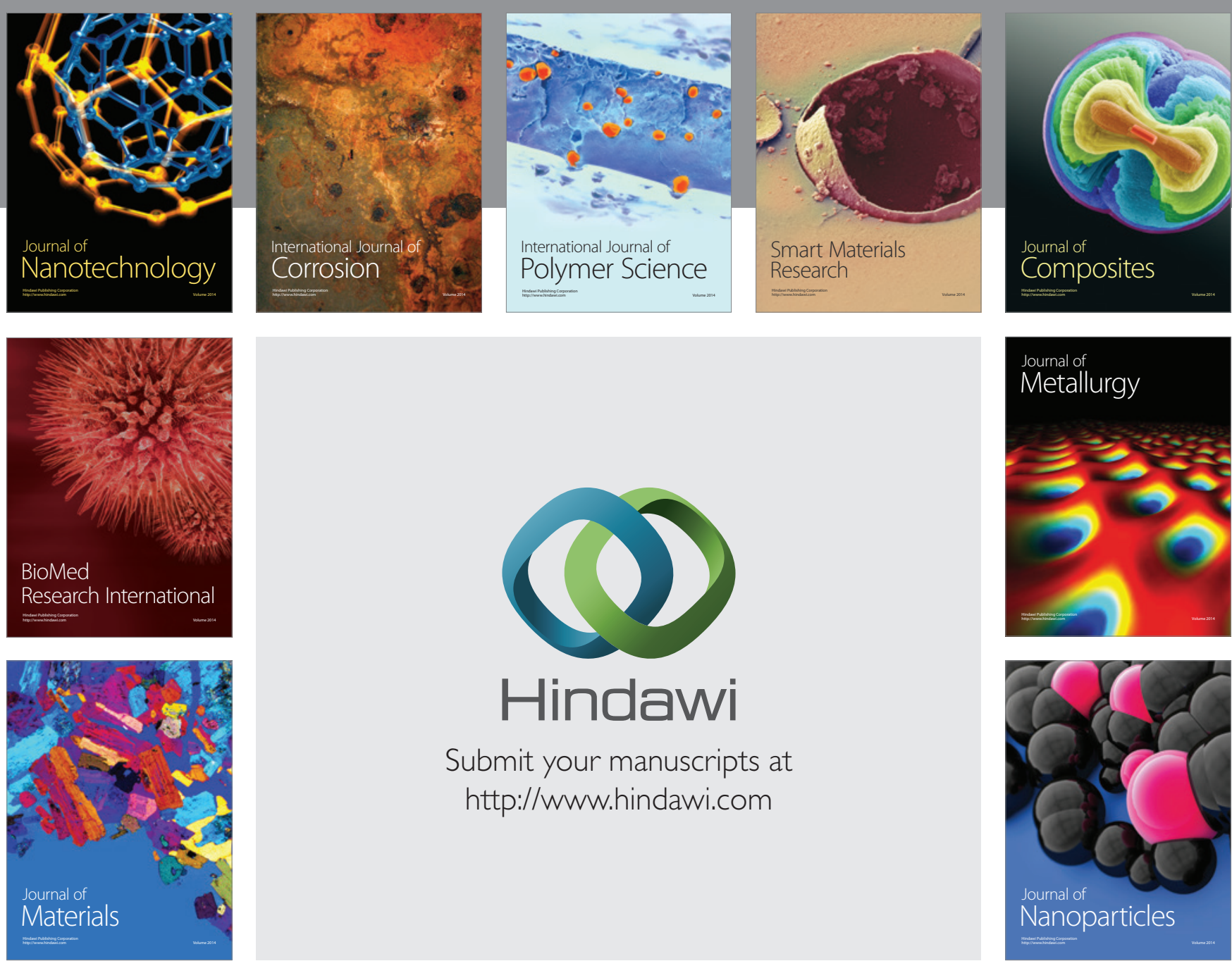

\section{Hindawi}

Submit your manuscripts at

http://www.hindawi.com

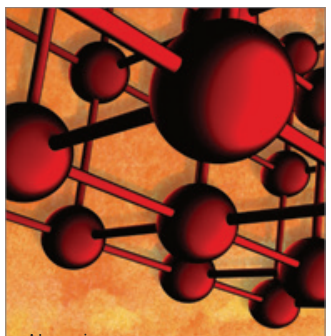

Materials Science and Engineering
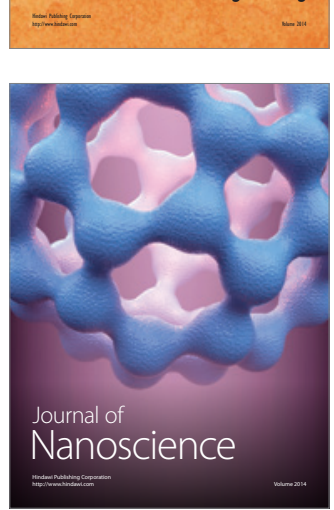
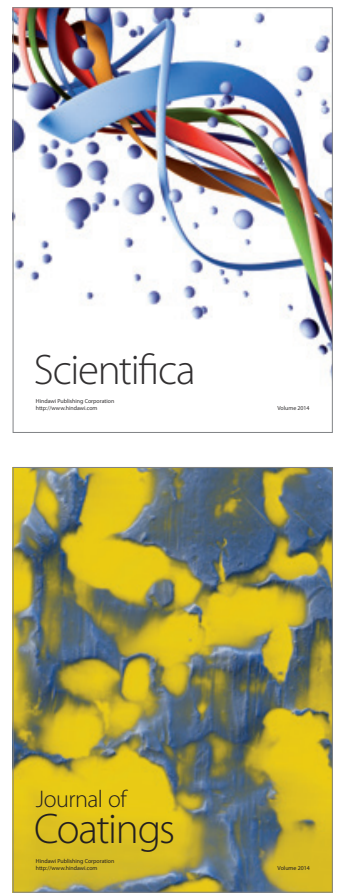
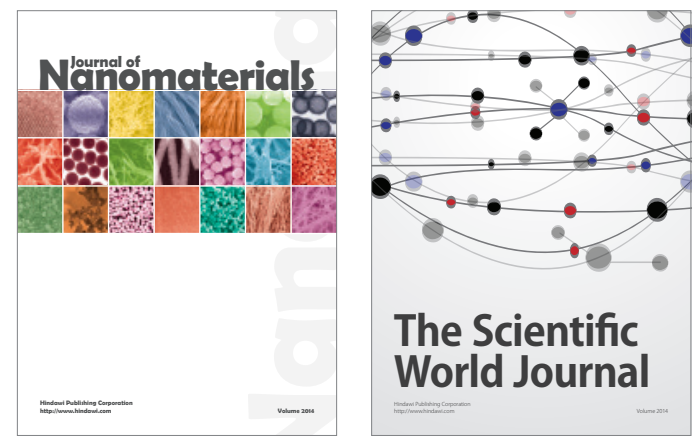

The Scientific World Journal
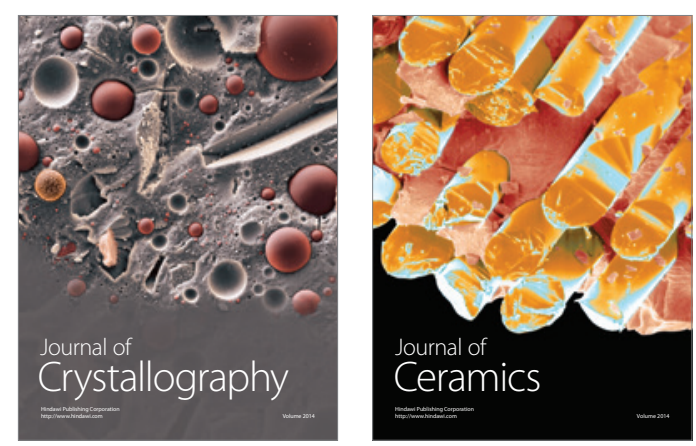
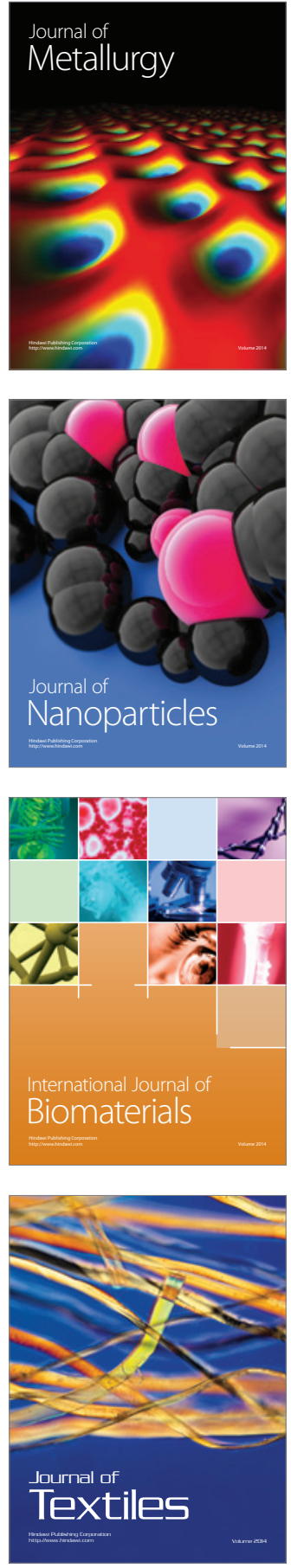